\title{
Interactive comment on "Measurement report: Short-term variation of ammonia concentration in an urban area: contributions of mist evaporation and emissions from a forest canopy with bird droppings" by Kazuo Osada
}

Anonymous Referee \#1

Received and published: 20 May 2020

The author reports two years of $\mathrm{NHx}$ and $\mathrm{NH} 4+$ data collected in Nagoya, Japan, and uses it to infer local sources of $\mathrm{NH} 3$, such as traffic, plant stomata, soil pore water, and bird droppings. Observations of NH3 are consistent with other studies (e.g., daytime maximum, strong seasonal variations), and data are presented in a fairly clear manner. The most novel part of the manuscript is the finding that bird droppings could be a relevant local source of $\mathrm{NH} 3$ in urban areas. Although the manuscript is fairly well written, phrasing and grammar could be improved throughout the manuscript. Portions of the data analysis and discussion could be expanded to improve the manuscript, as noted 
below. Nonetheless, this measurement report contains valuable insight for understanding urban ammonia sources, and publication is recommend once the comments below are addressed.

\section{General Comments:}

Most of the data analysis only considers parts of the data set (e.g., July/December 2018 , and $\mathrm{RH}<70 \%$ when wind speed $<3 \mathrm{~m} / \mathrm{s}$ ). A more holistic look at the entire data set might give additional insight on various sources.

For example, the morning $\mathrm{NH} 3$ peak $\sim 2-4$ hours after sunrise is decoupled from the maximum ambient temperature which is inconsistent with bi-directional exchange (i.e., stomata and soil) driving NH3 emissions, since these emissions should peak with temperature. Is it possible the lack of a coincident peak of $\mathrm{NH} 3$ and temperature is caused by enhanced vertical mixing (i.e., dilution) later in the day?

Furthermore, examining days with presumed surface wetness (i.e., $\mathrm{RH}>70 \%$ ) might provide insight on whether or not the morning peak in Fig. 4 (top left) is related to evaporation of surface wetness. In other words, the different peak times for $\mathrm{NH} 3$ and temperature, as well as the impact of surface wetness evaporation should be explored further.

Specific Comments:

Line 108 - what was the measurement height above the ground?

Lines 108 to 124 - what is the approximate residence time of the air sample, and distance it travels from the inlet, before it comes into contact with the water droplets (i.e., is dissolved)? Is it possible that some relevant fraction of $\mathrm{NH} 3$ partitions to the surface of the sampling inlet, which could desorb later at high temperatures and/or lower $\mathrm{NH} 3$ concentrations? In other words, has collection efficiency of the system been tested?

Lines 144 to 145 - presumably diurnal variation in wind speed is not as clear in winter- 
time due to the lack of sea breeze circulations, although the current phrasing implies a direct link between sunlight and wind speed. Recommend rephrasing to clarify that it's not sunlight that's directly impacting wind speed.

Section 3.1 - the analysis focuses on only two months (July and December 2018). Is there a reason that more months weren't considered (e.g., Dec 2017, July 2019, Nov/Jan, June/Aug) when trying to interpret seasonal differences? Considering these additional months would likely make the analysis more representative of the winter/summer seasons.

Section 3.2 - there is a lot of discussion about mist/droplet $\mathrm{pH}$; however, the impact of $\mathrm{pH}$ on $\mathrm{NH} 3$ release from evaporating mist/droplets is not made clear. It would be helpful to provide a few sentences explicitly stating how $\mathrm{NH} 3$ emissions from droplets are impacted by $\mathrm{pH}$.

Lines 226 to 227 - the assumption is that the air being sampled before sunrise under low wind conditions reflects local sources. However, is it possible that the nocturnal boundary layer is sufficiently shallow during these times, such that the sampling inlet on the 7th floor is above the nocturnal boundary and is decoupled from surface sources?

Lines 303 to 306 - the description of crow abundance and behaviour is very anecdotal. A more detailed description on what is meant by terms like "visual impression" and "rarely observed" would be useful.

Line 322 - is this a unit conversion error (3.4 mol m-2 day- 1 to $100 \mathrm{mmol} \mathrm{m}-2$ month-1)?

Figure $1 b$ - please add a scale for distance.

Interactive comment on Atmos. Chem. Phys. Discuss., https://doi.org/10.5194/acp-2020-244, 2020. 